\title{
ESTRUCTURA MORFO-ANATÓMICA Y SALIDA DE DORMICIÓN FÍSICA DE LAS SEMILLAS DE MALVASTRUM COROMANDELIANUM SSP. COROMANDELIANUM (MALVACEAE)
}

\author{
MORPHO-ANATOMICAL STRUCTURE AND PHYSICAL DORMANCY BREAKING OF \\ MALVASTRUM COROMANDELIANUM SSP. COROMANDELIANUM (MALVACEAE) \\ SEEDS
}

\author{
Guadalupe Galíndez $z^{1,2^{*}}\left(\mathbb{D}\right.$, Diego López-Spahr ${ }^{1,2} \mathbb{D}$, Carlos Anselmo Gómez $z^{2,3}(\mathbb{D}$, \\ Valeria Pastrana-Ignes ${ }^{1}\left(\mathbb{D}\right.$, Rita Díaz ${ }^{1}$ (D) Tania Bertuzzi ${ }^{4}$ 'D y Pablo Ortega-Baes ${ }^{1}$ (D)
}

1. Laboratorio de Investigaciones Botánicas (LABIBO), Facultad de Ciencias Naturales, Universidad Nacional de Salta-CONICET, Av. Bolivia 5150, Salta, 4400, Argentina. 2. Sede Regional Metán-Rosario de la Frontera, UNSa, Coronel Vidt 346, Metán, 4440, Salta, Argentina. 3. Laboratorio de Microscopía Electrónica de Barrido (LASEM), UNSa, Salta, Argentina.

4. Centro de Investigaciones y Transferencia de Catamarca (CITCA), CONICET-UNCA, Prado 366, San Fernando del Valle de Catamarca (4700), Catamarca, Argentina.

*galindez@natura.unsa.edu.ar

\section{Citar este artículo}

GALÍNDEZ, G., D. LÓPEZ-SPAHR, C. ANSELMO GÓMEZ, V. PASTRANAIGNES, R. DÍAZ, T. BERTUZZI \& P. ORTEGA-BAES. 2019. Estructura morfo-anatómica y salida de dormición física de las semillas de Malvastrum coromandelianum ssp. coromandelianum (Malvaceae). Bol. Soc. Argent. Bot. 54: 509-517.

DOI: http://dx.doi. org/10.31055/1851.2372.v54. n4.24162

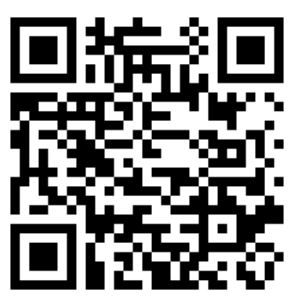

Recibido: 29 Abril 2019

Aceptado: 27 Agosto 2019

Publicado: 15 Diciembre 2019

Editora: Ana María Gonzalez (DD

ISSN versión impresa 0373-580X ISSN versión on-line 1851-2372

\section{SUMMARY}

Background and aims: The occurrence of seeds with physical dormancy is an obstacle for the use and management of many plant species. Here, we studied the presence of physical dormancy in mericarps (seed-dispersal units) and seeds, the morphoanatomical structures responsible for physical dormancy, and the effects of possible methods for breaking dormancy in seeds of Malvastrum coromandelianum (Malvaceae). M\&M: Imbibition essays were used to confirm the presence of physical dormancy in mericarps and seeds, and the morpho-anatomical seed structure was described by using a scanning electron microscopy. The effects of mechanical, chemical and thermal scarifications on seed germination and seed structure were also evaluated.

Results: Mericarps and scarified seeds increased $>160 \%$ of their initial weight, whereas intact seeds increased $<40 \%$ of their initial weight. The presence of a palisade cell layer in seed coat and a water-gaps complex in the chalazal region were observed. Higher germination percentages and lower $t_{50}$ were registered after mechanical scarification, followed by chemical and thermal scarifications (dry heat). Chemical and thermal scarifications caused the chalazal cap elimination and the contiguous cracks to form around the chalazal region; whereas the formation of a chalazal blister and its elimination were only observed after chemical scarification.

Conclusions: Seeds of $M$. coromandelianum have physical dormancy. Water enters the seeds through a water-gap complex (Type III compound) located in the chalazal region. Mechanical, chemical and thermal scarifications are effective methods for breaking physical dormancy and increase germination.

\section{KEY WORDS}

Malvastrum coromandelianum, physical dormancy, scarification, seed morpho-anatomy, water-gap complex.

\section{RESUMEN}

Introducción y objetivos: Uno de los principales problemas para el manejo y uso de muchas especies vegetales es la presencia de semillas con dormición física. En este trabajo estudiamos la presencia de dormición física en mericarpos (unidad de dispersión) y semillas, las estructuras morfo-anatómicas involucradas y los métodos de salida de dormición física en semillas de Malvastrum coromandelianum (Malvaceae).

M\&M: Se realizaron ensayos de imbibición en mericarpos y en semillas intactas y escarificadas. Se describió la estructura morfo-anatómica de las semillas con microscopio electrónico de barrido y se evaluó el efecto de la escarificación mecánica, química y térmica sobre la germinación y estructura de las semillas.

Resultados: Los mericarpos y las semillas escarificadas incrementaron $>160 \%$ su peso inicial, mientras que las semillas intactas incrementaron $<40 \%$ su peso. Las semillas presentaron una cubierta con células en empalizada y un complejo de abertura al agua ubicado en la región chalazal. Los mayores porcentajes y menores $t_{50}$ se registraron luego de la escarificación mecánica, seguido de la química y térmica (calor seco). Las escarificaciones química y térmica produjeron la eliminación de la tapa chalazal y formación de grietas alrededor de la región chalazal, mientras que la formación y eliminación de una ampolla chalazal sólo se observó luego de la escarificación química.

Conclusiones: Las semillas de $M$. coromandelianum presentan dormición física. EI ingreso de agua ocurre a través de un complejo de abertura (Tipo III compuesto) en la región chalazal de las semillas. Las escarificaciones mecánica, química y térmica son métodos eficientes para la salida de la dormición física y germinación de semillas.

\section{Palabras clave}

Complejo de abertura al agua, dormición física, escarificación, Malvastrum coromandelianum, morfo-anatomía de semilla. 


\section{INTRODUCCIÓN}

La dormición física (DF) ha sido citada en al menos 18 familias de Angiospermas, incluyendo Anacardiaceae, Bixaceae, Fabaceae y Malvaceae (Baskin \& Baskin, 2014). Este tipo de dormición se atribuye a la presencia de cubiertas impermeables en las semillas o frutos, constituidas por una o más capas de células en empalizada (macroesclereidas o células de Malpighi) impregnadas de sustancias hidrofóbicas (cutinas, ligninas, pectinas y ceras; Rolston, 1978). En especies de Anacardiaceae, Lauraceae, Nelumbonaceae y Surianaceae, se ha indicado que el pericarpo es el impermeable al agua y no la cubierta de la semilla (Baskin \& Baskin, 2014). En semillas con DF, el ingreso de agua ocurre por una región morfo-anatómica especializada, conocida como complejo de abertura al agua (water-gap complex), cuyo origen, ubicación y complejidad varía entre familias, subfamilias e incluso entre tribus (Gama-Arachchige et al., 2013; Baskin \& Baskin, 2014).

Gama-Arachchige et al. (2011), describieron la adquisición de la dormición física y la ontogenia del complejo de abertura al agua en semillas de Geranium carolinianum (Geraniaceae) y utilizaron este término para incluir: (1) la abertura que se forma cuando la DF se rompe, (2) las estructuras especializadas que obstruyen o cierran la abertura y (3) cualquier tejido especializado asociado a ellas. Asimismo, Gama-Arachchige et al. (2013) estudiando semillas de 15 especies de Bixaceae, Cistaceae, Cucurbitaceae, Fabaceae, Malvaceae, Nelumbonaceae, Rhamnaceae y Sapindaceae con distintos hábitos de crecimiento, formas de vida y procedencias (Norte América, China, Australia y Francia) clasificaron a los complejos de abertura al agua en tres tipos. El complejo de Tipo I se caracteriza por presentar aberturas lineales obstruidas por células en empalizadas alargadas modificadas; el de Tipo II presenta aberturas lineales o circulares obstruidas por estructuras en forma de tapa constituidas por células en empalizada y el de Tipo III presenta aberturas lineales o circulares obstruidas por estructuras en forma de tapón formadas por células de esclerénquima impermeables al agua. Por último, estos autores indicaron que los complejos pueden ser simples, si solo un tipo de abertura está involucrado en el ingreso inicial de agua, o compuestos si dos o más tipo de aberturas están involucradas en el proceso de dormición.

En condiciones naturales, la abrasión mecánica por el suelo, la temperatura (altas, bajas o fluctuantes), el contenido de humedad del suelo y el paso a través del tracto digestivo de animales han sido mencionados como algunos de los factores que intervendrían en la salida de DF (Van Assche \& Vandelook, 2006; Geneve et al., 2018). Así, por ejemplo, en ambientes sometidos a fuegos recurrentes, las altas temperaturas a las que estarían expuestas las semillas favorecerían la salida de este estado (Carreras et al. 2012; Baskin \& Baskin, 2014). En condiciones de laboratorio, la escarificación mecánica, química (ácido sulfúrico) y térmica (calor seco o húmedo) y el almacenamiento en seco, facilitarían la salida de dormición y por lo tanto la germinación de las semillas (OrtegaBaes et al., 2002; Daws et al., 2006; Galíndez et al., 2010, 2015, 2016; Baskin \& Baskin, 2014). A nivel de la estructura de las semillas, se ha indicado que estos tratamientos producirían daños en la cubierta seminal a través de la formación de grietas o espacios entre las células en empalizada y el desprendimiento de tejidos asociados a la DF, permitiendo el ingreso de agua a las semillas (Daws et al., 2006; Baskin \& Baskin, 2014; Erickson et al., 2016).

En Malvaceae, las especies de la subfamilia Malvoideae (tribu Malveae) se caracterizan por la presencia de un complejo de abertura al agua en la región chalazal, de Tipo III, formado por: (1) un tejido residual materno externo con forma de tapa (tapa chalazal) que sella desde el exterior dicha región, (2) una hendidura delimitada por células en empalizada (hendidura chalazal) y (3) un tejido parenquimático con forma de tapón (tapón chalazal) que sella, desde el interior, la hendidura. Asimismo, se ha indicado que el complejo es compuesto, es decir que el ingreso del agua ocurre por dos aberturas, primariamente a través de una ampolla (ampolla chalazal) que se forma y desprende en el extremo opuesto al hilo y secundariamente por la hendidura chalazal (Egley \& Paul, 1981; Kildisheva et al., 2011; Gama-Arachchige et al., 2013; Baskin \& Baskin, 2014; Packa et al., 2014; Erickson et al., 2016). Sin embargo, son pocos los estudios que han evaluado en forma conjunta el efecto de distintos tratamientos sobre las estructuras morfo-anatómicas involucradas en la DF y la salida de este estado. 


\section{G. Galíndez et al. - Dormición física en semillas de Malvastrum coromandelianum}

El objetivo de este trabajo fue estudiar la presencia de DF en mericarpos (unidad de dispersión) y en semillas de Malvastrum coromandelianum ssp. coromandelianum (Malvaceae); una especie de distribución cosmopolita, de importancia agronómica y con un alto valor de uso medicinal. Específicamente: (i) evaluamos la presencia de DF en mericarpos y en semillas, (ii) caracterizamos la estructura morfo-anatómica de las semillas (cubierta seminal y complejo de abertura al agua), (iii) determinamos los métodos más adecuados para la salida de DF y (iv) identificamos los cambios en el complejo de abertura asociados a la salida de DF. Se espera que: (i) las semillas (no los mericarpos) presenten DF; (ii) el ingreso de agua a las semillas ocurra a través de un complejo especializado de abertura al agua de Tipo III compuesto; (iii) las escarificaciones mecánica, química y térmica sean métodos eficientes de ruptura de la DF y (iv) las escarificaciones química y térmica generen cambios morfo-anatómicos en el complejo de abertura que permitan el ingreso de agua y por lo tanto la germinación de las semillas.

\section{Materiales y MÉtodos}

\section{Especie estudiada}

Malvastrum coromandelianum ssp. coromandelianum (L.) Garcke (Malvoideae, Malveae), conocida como afata o escoba dura, es una hierba o subarbusto perenne de hasta $150 \mathrm{~cm}$ de altura. Presenta flores agrupadas en glomérulos plurifloros con corola amarilla. El fruto es un esquizocarpo con 11-13 mericarpos uniovulados, indehiscentes de $\leq 2 \mathrm{mg}$ (Krapovickas \& Tolaba, 2012). Florece y fructifica desde verano hasta mediados o fines de otoño. Es una especie de origen americano, ampliamente distribuida en regiones tropicales, subtropicales y templadas de todo el mundo (Krapovickas \& Tolaba, 2012). En Argentina se la encuentra en las regiones del noroeste, noreste y centro del país (Zuloaga et al., 2008), frecuentemente en terrenos abandonados, disturbados por fuego (Carreras et al., 2012) y bordes de caminos. Ha sido citada como maleza y hospedante de virus de cultivos y como fuente de forraje (Jiang \& Zhou, 2005; Krapovickas \& Tolaba, 2012). Además, varias partes de la planta son utilizadas en la preparación de infusiones que se utilizan como hepato protectores, purgantes, contra infecciones y para curar la ictericia y la diabetes (Sanghai et al., 2013).

\section{Colecta de semillas}

Durante la época de dispersión natural (mayojunio) de 2017, se colectaron numerosos frutos (esquizocarpos) maduros de al menos 30 plantas en la localidad de Villa San Lorenzo, Salta $\left(24^{\circ}\right.$ $\left.46^{\prime} \mathrm{S}, 65^{\circ} 29^{\prime} \mathrm{O}\right)$. En el laboratorio, se limpiaron $\mathrm{y}$ seleccionaron los mericarpos llenos (i.e., con semillas) no infestados por insectos o por otro tipo de daño, los que fueron almacenados en bolsas de papel a temperatura ambiente $\left(\right.$ c. $\left.21^{\circ} \mathrm{C}, 50 \% \mathrm{HR}\right)$ hasta su utilización en los ensayos de germinación ( $\leq 15$ días). La viabilidad inicial de las semillas se evaluó en 100 semillas sanas, utilizando la técnica de tinción con cloruro de tetrazolio (ISTA, 2017), la que fue del $98 \%$.

\section{Presencia de dormición física}

Para determinar la presencia de cubiertas impermeables al agua en los mericarpos, se pesaron tres lotes de 25 mericarpos cada uno con una balanza de precisión (Denver Instrument APX-200) y se sembraron en cajas de Petri sobre agar al $1 \%$ en agua a $20 \pm 2{ }^{\circ} \mathrm{C}$ con luz blanca (fotoperíodo 8/16 hs luz-oscuridad; Galíndez et al., 2010). A las $24 \mathrm{~h}$, cada lote se colocó sobre papel de filtro (para eliminar la humedad superficial) y se pesaron nuevamente. La presencia de DF en las semillas sin mericarpo se evaluó mediante ensayos de imbibición (curvas de imbibición). Para ello, inicialmente se pesaron tres lotes individuales de 25 semillas intactas y tres lotes de 25 semillas con escarificación mecánica (obtenida mediante un corte con escalpelo en la región opuesta al micrópilo), los que fueron sembrados e incubados en las mismas condiciones que los mericarpos. A intervalos de $2 \mathrm{~h}$ para las primeras $8 \mathrm{~h}$ y luego cada $24 \mathrm{~h}$ se pesaron nuevamente cada uno de los lotes. El experimento continuó hasta que la mayoría de las semillas escarificadas mecánicamente germinaron. Se estimó el incremento relativo de peso (IRP, en base al peso fresco inicial) en los mericarpos y en las semillas intactas y con escarificación mecánica, mediante la fórmula: IRP $(\%)=[($ peso final - peso inicial) / peso inicial] x 100 (ISTA, 2017).

Debido a que los mericarpos presentaron cubiertas permeables al agua (ver resultados), la 
estructura morfo-anatómica y los métodos de salida de dormición fueron evaluados sólo en las semillas.

\section{Estructura morfo-anatómica de las semillas}

Para describir la estructura morfo-anatómica de las semillas se procesaron 10 semillas, las que fueron preparadas para el análisis con Microscopio Electrónico de Barrido (MEB). Para ello, las semillas fueron deshidratadas con una serie creciente de alcoholes, secadas por punto crítico con $\mathrm{CO}_{2}$ y posteriormente bañadas con oro (D'Ambrogio, 1986). Se tomaron microfotografías con el MEB (JEOL-JSM 5480 LV) de semillas intactas en cortes longitudinales y transversales (ver Fig. 1).

\section{Salida de dormición física}

Para determinar los mejores métodos de salida de DF de semillas se realizaron los siguientes tratamientos: 1) escarificación mecánica: mediante un corte con escalpelo en la región opuesta al micrópilo; 2) escarificación química: las semillas se sumergieron en ácido sulfúrico (98\%) durante 10, 20 y 30 minutos; 3) escarificación térmica con calor húmedo: las semillas se sumergieron en agua destilada a 60,80 y $100^{\circ} \mathrm{C}$ durante dos minutos; 4) escarificación térmica con calor seco: las semillas se colocaron en estufa a $90^{\circ} \mathrm{C}$ durante 10,20 y 30 minutos y 5) semillas intactas (utilizadas como control). Luego de la aplicación de cada tratamiento, cuatro repeticiones de 25 semillas fueron colocadas en cajas de Petri con agar al $1 \%$ en agua e incubadas en una cámara de germinación a $20 \pm 2^{\circ} \mathrm{C}$ con luz blanca (fotoperíodo $8 / 16 \mathrm{~h}$ luz/ oscuridad). Los tratamientos se eligieron con base en los resultados obtenidos por Galíndez et al. (2010). Los recuentos de germinación se realizaron diariamente por un período de 30 días, tomando como criterio de germinación la emergencia de la radícula $(\geq 1 \mathrm{~mm})$. Al finalizar el ensayo, se cortaron las semillas que no germinaron para determinar su viabilidad; las semillas que permanecieron blancas y turgentes fueron consideradas viables. A partir de los datos obtenidos, se estimó el porcentaje de semillas germinadas en base al número total de semillas viables (i.e., semillas germinadas + semillas viables) y el tiempo (en días) para la germinación del $50 \%$ del total de semillas germinadas $\left(t_{50}\right)$.

Para evaluar los cambios morfo-anatómicos en el complejo de abertura luego de la aplicación de la escarificación química y térmica, se utilizaron
40 semillas. Diez semillas fueron escarificadas con ácido sulfúrico (30 min), 10 con calor húmedo (inmersión durante $2 \mathrm{~min}$ en agua a $100^{\circ} \mathrm{C}$ ), 10 con calor seco (en estufa a $90^{\circ} \mathrm{C}$ durante 30 minutos) y 10 permanecieron intactas como control (sin escarificar). Las mismas fueron preparadas para el análisis con el MEB y microfotografiadas, siguiendo la metodología previamente mencionada.

\section{Análisis estadístico}

Para determinar los efectos de los distintos tratamientos de salida de dormición sobre el porcentaje de semillas germinadas, se utilizaron modelos lineales generalizados (GLMs) con distribución de errores binomial y función de enlace logit en R (R Core Team, 2016). El número de semillas germinadas fue usado como variable dependiente, especificando la cantidad de semillas viables en cada unidad experimental, mientras que los tratamientos fueron considerados como factores fijos. Se estimaron mediante intervalos de confianza las proporciones promedio con la función lsmeans del paquete R. Los efectos de los tratamientos sobre el $t_{50}$ fueron analizados con un análisis de varianza a una vía (ANOVA). En ambos casos, se utilizó la prueba DGC (Di Rienzo et al., 2002) para comparar las medias cuando los efectos resultaron significativos. Se utilizó el programa estadístico Infostat versión 2017 (Di Rienzo et al., 2017).

\section{Resultados}

\section{Presencia de dormición fisica}

Los mericarpos registraron en promedio un IRP de $163 \%$ luego de $24 \mathrm{~h}$ de imbibición $(35.5 \pm 2.8$ vs $93.5 \pm 13.5 \mathrm{mg}$ ). El IRP promedio de las semillas intactas fue de $35 \%(32.6 \pm 1.1 \mathrm{vs} 44.1 \pm 1.8 \mathrm{mg})$, mientras que para las semillas escarificadas fue de $165 \%(31.9 \pm 0.7$ vs $84.8 \pm 4.2 \mathrm{mg})$. El porcentaje de germinación de las semillas intactas fue $28 \pm 3 \%$, mientras que las semillas escarificadas germinaron el $100 \%$.

\section{Estructura morfo-anatómica de las semillas}

Las semillas presentaron un embrión curvo bien diferenciado, con el extremo de la radícula opuesto a los extremos de los cotiledones (Fig. 1A). Ambos extremos, corresponden morfológicamente a dos protuberancias, la del área micropilar (radícula) y la 

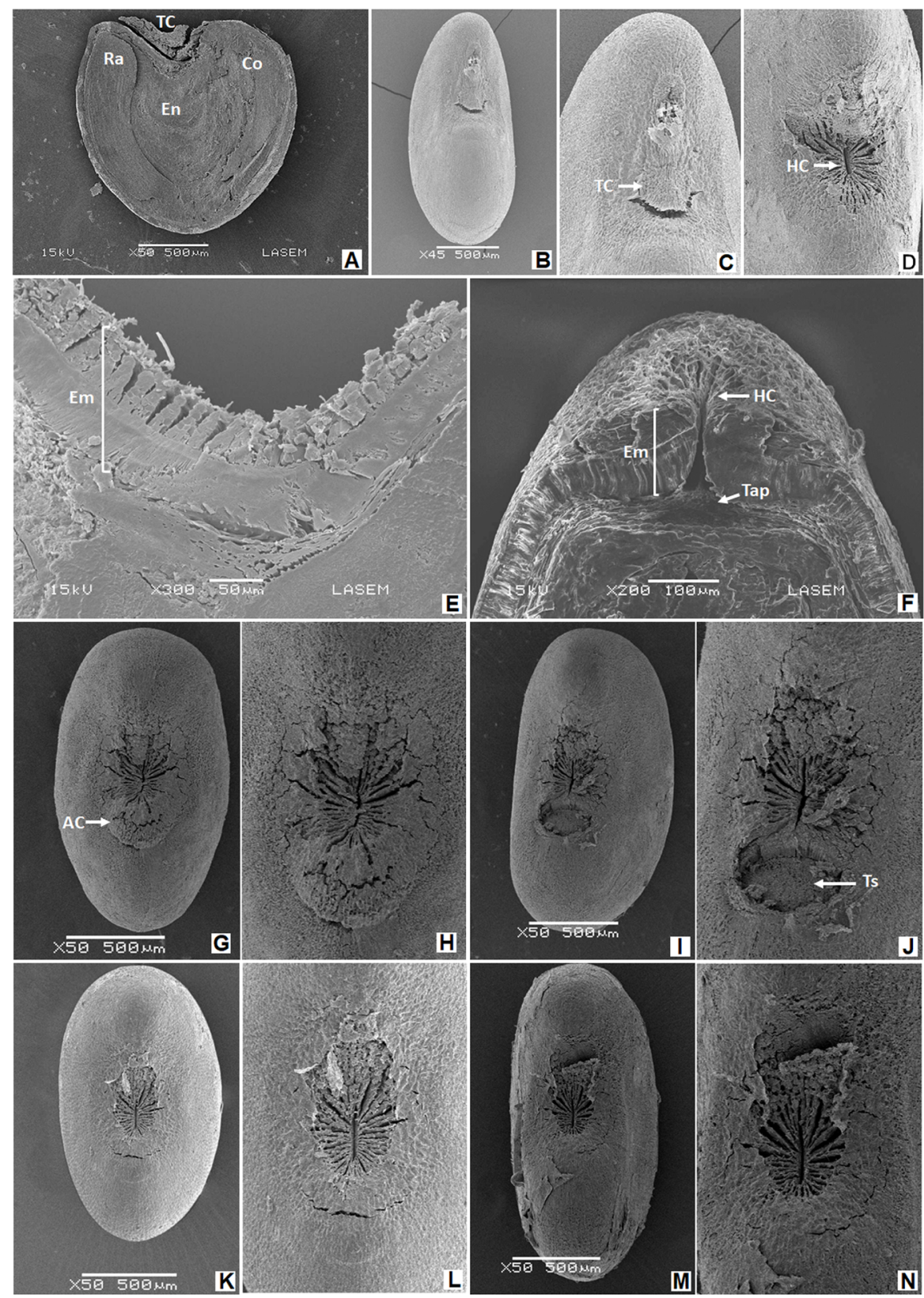

Fig. 1. Estructura de las semillas intactas y escarificadas de Malvastrum coromandelianum ssp. coromandelianum (MEB). A: Corte longitudinal de semilla intacta. B: Vista frontal de semilla intacta. C: Vista frontal de la región chalazal. D: Vista frontal de la región chalazal luego de la remoción de la tapa chalazal. E: Corte longitudinal de la hendidura chalazal de semilla intacta. F: Corte transversal de la hendidura chalazal de semilla intacta. G: Región chalazal luego de escarificación química (Ác. Sulfúrico: 30 min) donde se observa la ampolla. H: detalle de G. I: Región chalazal luego de escarificación química (ác. sulfúrico: $30 \mathrm{~min}$ ) donde se observa el tejido subyacente luego del desprendimiento de la ampolla. J: detalle de I. K: Región chalazal luego de escarificación térmica con calor húmedo (2 min a $\left.100^{\circ} \mathrm{C}\right)$. L: detalle de K. M: Región chalazal luego de escarificación térmica con calor seco $\left(30\right.$ minutos a $\left.90^{\circ} \mathrm{C}\right)$. $\mathbf{N}$ : Detalle de M. Abreviaturas= AC: ampolla chalazal, Co: cotiledones, Em: células en empalizada, En: endosperma, HC: hendidura chalazal, Ra: radícula, Tap: tapón chalazal, TC: tapa chalazal, Ts: tejido subyacente. 
del área chalazal (cotiledones). En el área chalazal se registró la presencia de un tejido materno residual en forma de una tapa (tapa chalazal; Fig. 1A, B, C). Cuando se eliminó dicha tapa se observó una fisura o hendidura delimitada por células en empalizada dispuestas en forma radial (hendidura chalazal; Fig. 1D, E). En el corte transversal a nivel de la hendidura chalazal se observó la presencia de la cubierta seminal formada por células en empalizadas y en el interior un tejido de parénquima con forma de tapón (tapón chalazal; Fig. 1F).

\section{Salida de dormición}

El mayor porcentaje de germinación se registró en las semillas escarificadas mecánicamente (>95\%), seguido de los tratamientos de ácido sulfúrico (20 y
$30 \mathrm{~min}$ ) y de los de calor seco (todos los tiempos; Tabla 1). Los $t_{50}$ fueron significativamente mayores en las semillas intactas y en las escarificadas térmicamente con calor húmedo a $100^{\circ} \mathrm{C}$ (Tabla 1).

Todos los tratamientos provocaron la eliminación de la tapa chalazal y la formación de espacios o grietas (ruptura de los tejidos en empalizada) en la región chalazal (Fig. 1G, H, I, J). En las semillas sometidas a escarificación química se observó además el levantamiento de la capa de células en empalizada en la región chalazal opuesta al micrópilo, es decir la formación de una ampolla (Fig. 1G). Asimismo, en otras semillas sometidas a este mismo tratamiento, se observó el tejido subyacente a las células en empalizada resultado del desprendimiento de la ampolla.

Tabla 1. Porcentaje de semillas germinadas (media $\pm 95 \%$ intervalo de confianza) y tiempo (en días) para la germinación del $50 \%$ de las semillas $\left(t_{50}\right.$, media \pm error estandar) para cada tratamiento evaluado. Tratamientos con letras iguales no difieren estadísticamente $(p>0.05)$ de acuerdo con la prueba post hoc DGC.

\begin{tabular}{|c|c|c|}
\hline Tratamiento & Germinadas (\%) & $t_{50}$ (días) \\
\hline Intactas & $11(7.8 ; 4.8) \mathrm{d}$ & 13.89 (1.19) a \\
\hline Escarificación mecánica & $96(2.5 ; 6.2) a$ & $0.87(0.16) \mathrm{c}$ \\
\hline \multicolumn{3}{|l|}{ Escarificación química } \\
\hline Ácido Sulfúrico (10 min) & $52(9.6 ; 9.0) c$ & $1.90(0.76) c$ \\
\hline Ácido Sulfúrico (20 min) & $75(7.5 ; 9.4) b$ & $1.87(0.06) \mathrm{c}$ \\
\hline Ácido Sulfúrico (30 min) & $63(8.9 ; 9.9) b$ & $1.82(0.49) \mathrm{c}$ \\
\hline \multicolumn{3}{|l|}{ Escarificación térmica } \\
\hline Calor húmedo $\left(60^{\circ} \mathrm{C}\right)$ & $48(9.7 ; 9.6) \mathrm{c}$ & $4.31(0.50) c$ \\
\hline Calor húmedo $\left(80^{\circ} \mathrm{C}\right)$ & $46(9.8 ; 9.5) c$ & $9.69(0.95) b$ \\
\hline Calor húmedo $\left(100^{\circ} \mathrm{C}\right)$ & $23(9.2 ; 7.3) \mathrm{d}$ & $12.88(1.47) \mathrm{a}$ \\
\hline Calor seco (10 min) & $65(8.7 ; 9.8) b$ & $1.05(0.09) \mathrm{c}$ \\
\hline Calor seco (20 min) & $60(9.1 ; 9.9) b$ & $0.84(0.05) c$ \\
\hline Calor seco (30 min) & $60(10.0 ; 8.9) b$ & $0.81(0.09) c$ \\
\hline
\end{tabular}




\section{G. Galíndez et al. - Dormición física en semillas de Malvastrum coromandelianum}

\section{Discusión}

La dormición física es causada por la impermeabilidad al agua de las cubiertas de los frutos o semillas (Baskin \& Baskin, 2014). Para especies de Anacardiaceae, Lauraceae (solo el género Cassytha), Nelumbonaceae y Surianaceae, el pericarpo de los frutos es el impermeable al agua, por lo que la imposibilidad de germinar estaría impuesta por las cubiertas del fruto y no de las semillas (Baskin \& Baskin, 2014). En este trabajo registramos que los mericarpos de $M$. coromandelianum fueron permeables al agua ya que, incrementaron más del $160 \%$ su peso inicial. En el caso de las semillas sin mericarpo encontramos que, en semillas intactas, el incremento en peso fue menor al $40 \%$, con un $30 \%$ de semillas germinadas, mientras que en las escarificadas el incremento fue superior al $160 \%$, con un $100 \%$ de semillas germinadas. Estos resultados indican que los mericarpos no presentan ningún impedimento físico al ingreso de agua, siendo las semillas las que presentan una cubierta impermeable al agua. Resultados similares han sido registrados para otras especies de Malvaceae, indicando que las semillas, no el pericarpo, son las que presentan DF (Daws et al., 2006; Galíndez et al., 2010; Baskin \& Baskin, 2014; Packa et al., 2014; Geneve et al., 2018).

La impermeabilidad de la cubierta seminal ha sido atribuida a la presencia de una o más capas de células en empalizada, impregnadas de sustancias hidrofóbicas, por lo que el ingreso de agua ocurre por una región especializada (Baskin \& Baskin, 2014). Particularmente, para especies de la tribu Malveae se ha documentado la presencia un complejo de abertura al agua (Tipo III) ubicado en la región chalazal, donde la capa de células en empalizada se encuentra en forma discontinua. La discontinuidad resultante forma o delimita una fisura o hendidura (hendidura chalazal), sellada externamente por un tejido residual materno (tapa chalazal) e internamente por células de parénquima en forma de tapón (tapón chalazal; Egley \& Paul, 1981; Gama-Arachchige et al., 2013; Packa et al., 2014). Esta descripción concuerda con lo observado en este estudio, ya que, las semillas presentaron una cubierta seminal formada por una capa de células en empalizada y en la región chalazal una tapa, una hendidura y un tapón chalazal. Así, las semillas de esta especie presentarían un complejo de abertura al agua de Tipo III, similar a lo documentado para otras especies de la Tribu Malveae.
Con relación a los métodos empleados para la salida de la dormición y por lo tanto para la germinación, se ha indicado que los mayores porcentajes de germinación en menores tiempo se registran luego de la escarificación mecánica, química y/o térmica (Baskin \& Baskin, 2014). En este estudio en particular, los mayores porcentajes y menores tiempos de germinación se registraron luego de la escarificación mecánica, seguida de los tratamientos de escarificación química con ácido sulfúrico y térmica con calor seco. Los altos valores observados en los dos primeros tratamientos son esperables y similares a los documentados para otras especies con DF ya que, mediante la escarificación mecánica y química, se remueve o elimina parte de la cubierta seminal, lo que permite el ingreso del agua sin ningún impedimento de tipo físico (ver Baskin \& Baskin, 2014). En el caso de la escarificación térmica con calor húmedo, los menores valores de germinación podrían indicar que las temperaturas evaluadas (particularmente a $100^{\circ} \mathrm{C}$ ) produjeron daños o muerte de los embriones o que su efecto no fue suficiente para romper la dormición; contrariamente a lo registrado para otras especies con DF (Baskin \& Baskin, 2014; Galíndez et al., 2010, 2015, 2016). Por otra parte, los mayores valores de germinación registrados luego de la escarificación térmica con calor seco son similares a los registrados para otras especies de Malvaceae procedentes de ambientes sometidos a incendios, sugiriendo que la germinación de estas especies podría estar estimulada por el fuego (Galíndez et al., 2010; Carbone et al., 2017; Arcamone \& Jaureguiberry, 2018). Así, se ha indicado que las especies con semillas pequeñas $(\leq 2 \mathrm{mg})$ enterradas en los primeros $\mathrm{cm}$ del suelo estarían sometidas a temperaturas entre 70 y $100^{\circ} \mathrm{C}$ durante fuegos moderados o de bajas intensidades, lo que favorecería la salida de dormición y por lo tanto la germinación (Baskin \& Baskin, 2014; Arcamone \& Jaureguiberry, 2018). Estos resultados permitirían explicar la distribución y abundancia de $M$. coromandelianum y de otras especies de Malvaceae presentes en ambientes sometidos a incendios recurrentes (Carreras et al., 2012) o antrópicos (Krapovickas \& Tolaba, 2012).

Por último, se ha indicado para especies de la tribu Malveae que las escarificaciones química $\mathrm{y} / \mathrm{o}$ térmica producen a nivel del complejo de abertura al agua: (1) la eliminación de la tapa chalazal, (2) la formación de grietas o espacios en las células en empalizada que delimitan la hendidura chalazal, 
(3) el desprendimiento del tapón chalazal por desagregación de las células parenquimáticas y (4) el levantamiento de las células en empalizadas en la región opuesta al hilo (i.e, formación de una ampolla chalazal), lo que permitiría el ingreso de agua a las semillas (Egley \& Paul, 1981; Packa et al. 2014; Baskin \& Baskin, 2014; Erickson et al., 2016). En este trabajo registramos un desprendimiento total de la tapa chalazal y la formación de grietas, luego de la aplicación de la escarificación química y térmica. Además, en las semillas escarificadas químicamente también se observó la formación y desprendimiento de la ampolla chalazal. Estos resultados, junto con los datos de germinación obtenidos en estos tratamientos, indicarían que la hendidura chalazal es el sitio principal de ingreso de agua y el desprendimiento de la ampolla chalazal el sitio secundario de ingreso del agua a las semillas; contrariamente a lo documentado para otras especies de la tribu Malveae, en donde el ingreso de agua ocurre principalmente por la ampolla y secundariamente por la hendidura chalazal (Egley \& Paul, 1981; Packa et al., 2014; Erickson et al., 2016). No obstante, nuevos estudios deberán realizarse con otras poblaciones de esta especie y en otras especies del género y de la tribu para corroborar estos resultados.

En síntesis, las semillas de Malvastrum coromandelianum ssp. coromandelianum: (1) presentan dormición física por lo que deben pasar por un proceso de escarificación para germinar; (2) el ingreso de agua a las semillas está asociado a un complejo de apertura al agua de Tipo III compuesto, ubicado en la región chalazal de las semillas; (3) el método más eficiente para la salida de la dormición es la escarificación mecánica seguida de las escarificaciones química y térmica con calor seco y (4) las escarificaciones química y térmica con calor seco producen cambios morfo-anatómicos en el complejo de abertura que permiten el ingreso de agua a las semillas y, por lo tanto, su germinación. Este es el primer estudio en el que se evaluó la presencia de dormición física, los mecanismos involucrados y los métodos de salida de este estado para una especie del género Malvastrum. Asimismo, la información generada en este trabajo puede contribuir a explicar la abundancia y distribución de esta especie en ambientes disturbados por el uso agrícola y/o por el fuego y al uso de semillas en programas de producción de plantas para uso medicinal.

\section{Contribución DE los AUtores}

GG diseñó la investigación, realizó el análisis e interpretación de datos, preparó las figuras y redactó y editó el manuscrito. DLS desarrolló ensayos de laboratorio, preparó las muestras para el MEB y la figura y editó el manuscrito. CAG preparó las muestras y obtuvo e interpretó las imágenes con el MEB. VPI y RD desarrollaron ensayos de laboratorio y prepararon las muestras para el MEB. TB recolectó frutos, acondicionó las semillas y realizó ensayos de laboratorio material. POB interpretó los datos y las imágenes con el MEB y editó el manuscrito. Todos los autores del trabajo participaron en la elaboración del manuscrito.

\section{Agradecimientos}

A Silvia Sühring por el asesoramiento con el análisis estadístico de los datos, a Ana Álvarez por su colaboración con los ensayos de laboratorio y a Cecilia Mamani por la determinación taxonómica de los ejemplares de herbario. El trabajo fue financiado por los proyectos del Consejo de Investigación de la Universidad Nacional de Salta (CIUNSa B N $\mathrm{N}^{\circ}$ 2409) y por el Instituto Nacional de Tecnología Agropecuaria (INTAPNBIO1131022).

\section{Bibliografía}

ARCAMONE, J. R. \& P. JAUREGUIBERRY. 2018. Germination response of common annual and perennial forbs to heat shock and smoke treatments in the Chaco Serrano, central Argentina. Austral ecology, 43: 567-577.

BASKIN, C. C. \& J. M. BASKIN. 2014. Seeds: Ecology, Biogeography, and Evolution of Dormancy and Germination. Academic Press, San Diego.

CARBONE, L. M., N. AGUIRRE ACOSTA, J. TAVELLA \& R. AGUILAR. 2017. Cambios florísticos inducidos por la frecuencia de fuego en el Chaco serrano. Bol. Soc. Argent. Bot. 52: 753-778.

CARRERAS, M. E., E. FUENTES, J. E. MARTINAT \& L. M. CARBONE. 2012. Reconocimiento de diásporas de Malveae (Malvaceae) en muestras de suelos de zonas serranas (Sierras Chicas, Córdoba, Argentina) afectadas por incendios. RodriguésiaInstituto de Pesquisas Jardim Botânico do Rio de Janeiro 63: 501-512. 


\section{G. Galíndez et al. - Dormición física en semillas de Malvastrum coromandelianum}

D’AMBROGIO,A. 1986. Manual de técnicas en histología vegetal. Editorial Hemisferio Sur, Buenos Aires.

DAWS, M. I., D. ORR, D. F. R. P. BURSLEM \& C. E. MULLINS. 2006. Effect of high temperature on chalazal plug removal and germination in Apeiba tibourbou Aubl. Seed Sci. Res. 34: 221-225. https://doi.org/10.15258/sst.2006.34.1.26

DI RIENZO, J. A., A. W. GUZMÁN \& F. CASANOVES. 2002. A multiple-comparisons method based on the distribution of the root node distance of a binary tree. J. Agric. Biol. Environ. Stat. 7: 129-142. https://doi.org/10.1198/10857110260141193

DI RIENZO, J. A., F. CASANOVES, M. G. BALZARINI, L. GONZALEZ, M. TABLADA \& C.W. ROBLEDO. InfoStat versión 2017. Grupo InfoStat, FCA, Universidad Nacional de Córdoba, Argentina. URL http://www.infostat.com.ar

EGLEY, G. H. \& R. N. PAUL JR. 1981. Morphological observations on the early imbibition of water by Sida spinosa (Malvaceae) seed. Am. J. Bot. 68: 1056-1065. https://doi.org/10.1002/j.1537-2197.1981.tb06389.x

ERICKSON, T. E., D. J. MERRITT \& S. R. TURNER. 2016. Overcoming physical seed dormancy in priority native species for use in arid-zone restoration programs. Austral. J. Bot. 64: 401-416.

https://doi.org/10.1071/BT16059

GALÍNDEZ, G., P. ORTEGA-BAES, C. E. SEAL, M. I. DAWS, A. L. SCOPEL \& H.W. PRITCHARD. 2010. Physical seed dormancy in Collaea argentina (Fabaceae) and Abutilon pauciflorum (Malvaceae). SeedSci. Technol. 38: 777-782. https://doi.org/10.15258/sst.2010.38.3.25

GALÍNDEZ, G., G. MALAGRINA, D. CECCATO, T. LEDESMA, L. LINDOW-LÓPEZ \& P. ORTEGABAES. 2015. Dormición física y conservación ex situ de semillas de Amburana cearensis y Myroxylon peruiferum (Fabaceae). Bol. Soc. Argent. Bot. 50: 153-161.

http://dx.doi.org/10.31055/1851.2372.v51.n1.14370

GALÍNDEZ, G., D. CECCATO, G. MALAGRINA, B. PIDAL, G. CHILO, H. BACH, R. FORTUNATO \& P. ORTEGA-BAES. 2016. Physical seed dormancy in native legume species of Argentina. Bol. Soc. Argent. Bot. 51: 73-78.

GAMA-ARACHCHIGE, N. S., J. M. BASKIN, R. L. GENEVE \& C. C. BASKIN. 2011. Acquisition of physical dormancy and ontogeny of the micropylewater-gap complex in developing seeds of Geranium carolinianum (Geraniaceae). Ann. Bot. 108:51-64. https://doi.org/10.1093/aob/mcr103

GAMA-ARACHCHIGE, N. S., J. M. BASKIN, R. L. GENEVE \& C. C. BASKIN. 2013. Identification and characterization of ten new water gaps in seeds and fruits with physical dormancy and classification of water-gap complexes. Ann. Bot. 112: 69-84. https://doi.org/10.1093/aob/mct094
GENEVE, R. L., C. C. BASKIN, J. M. BASKIN, K. G. JAYASURIYA \& N. S. GAMA-ARACHCHIGE. 2018. Functional morpho-anatomy of water-gap complexes in physically dormant seed. Seed Sci. Res. 28: 186-191. https://doi.org/10.1017/S0960258518000089

ISTA. 2017. International Rules for Seed Testing. International Seed Testing Association, Bassersdorf.

JIANG, T. \& X. ZHOU. 2005. Molecular characterization of a distinct begomovirus species and its associated satellite DNA isolated from Malvastrum coromandelianum ssp. coromandelianum in China. Virus Genes 31: 43-48. https://doi.org/10.1007/s11262-004-2198-z

KILDISHEVA, O. A., R. K. DUMROESE \& A. S. DAVIS. 2011. Overcoming dormancy and enhancing germination of Sphaeralcea munroana seeds. Hort Science 46: 1672-1676. https://doi.org/10.21273/HORTSCI.46.12.1672

KRAPOVICKAS, A. \& J. A. TOLABA. 2012. MALVACEAE Juss. Flora del Valle de Lerma. Aportes Botánicos de Salta, Serie Flora 8: 1-107.

ORTEGA-BAES, P., M. L. DE VIANA \& S. SÜHRING. 2002. Germination in Prosopis ferox seeds: effects of mechanical, chemical and biological scarifications. Journal of Arid Environments 50: 185-189. https://doi.org/10.1006/jare.2001.0859

PACKA, D., J. KWIATKOWSKI, Ł. GRABAN \& W. LAJSZNER. 2014. Germination and dormancy of Sida hermaphrodita seeds. Seed Sci. Technol. 42: 1-15. https://doi.org/10.15258/sst.2014.42.1.01

R DEVELOPMENT CORE TEAM. 2016. R: A language and environment for statistical computing. $\mathrm{R}$ Foundation for Statistical Computing, Vienna, Austria. ISBN 3-900051-07-0, Disponible en: http:// www.R-project.org.

ROLSTON, M. P. 1978. Water impermeable seed dormancy. Bot. Rev. 44: 365-396. https://doi.org/10.1007/BF02957854

SANGHAI, D. B., S. V. KUMAR, K. K., SRINIVASAN, H. N. ASWATHARAM \&C. S. SHREEDHARA. 2013. Pharmacognostic and phytochemical investigation of the leaves of Malvastrum coromandelianum (L.) Garcke. Anc Sci Life.33: 39-44. https://doi.org/10.4103/0257-7941.134596

VAN ASSCHE, J. A. \& F. E. A. VANDELOOK. 2006. Germination ecology of eleven species of Geraniaceae and Malvaceae, with special reference to the effects of drying seeds. Seed Sci. Res. 16: $283-$ 290. https://doi.org/10.1017/SSR2006255

ZULOAGA, F. O., O. MORRONE \& M. BELGRANO. 2008. Catálogo de las Plantas Vasculares del Conosur. Versión base de datos en sitio web del Instituto Darwinion. Argentina. Edición online: http://www2.darwin.edu.ar/Proyectos/ FloraArgentina/fa.htm [Acceso: Enero 2019]. 
